\title{
Anxiety Prevention in Indigenous Youth
}

\author{
Jenny Adermann and Marilyn Campbell \\ Queensland University of Technology, Kelvin Grove, \\ Queensland, Australia
}

\begin{abstract}
Anxiety is the most prevalent psychopathology in young people, with up to $18 \%$ suffering from one or more anxiety disorders. Early prevention is important, as many signs of anxiety are often evident in childhood and adolescence. Anxiety disorders have negative consequences for academic, social and individual outcomes, and have been shown to be a precursor to depression, suicide and substance abuse. It is important to focus on a general population health approach of embedding anxiety prevention programs in the school curriculum as well as providing targeted intervention for indicated and at risk groups. Although there are some excellent evidence-based anxiety and depression prevention programs for children and adolescents, there has been little research into the prevention of anxiety in minority populations such as Indigenous young people. While it is easy to hypothesise that Australian Indigenous youth may suffer high levels of anxiety, data to support this are scant. Issues of appropriate research methodology; differing constructs of mental health; variable stressors and protective factors; and difficulties with culturally appropriate assessments and interventions complicate studies. Prevention and early intervention anxiety programs need to be culturally sensitive and adapted for Indigenous youth. This paper argues for more research to be conducted on the specific prevention needs in this seemingly vulnerable population.
\end{abstract}

\section{Incidence of anxiety in youth}

While the last 15 years has seen research into childhood anxiety increase significantly, there has been little research on minority groups in this important area. This is especially so in examining anxiety disorders in Australian Indigenous youth. Recent data gathered in the Western Australian Aboriginal Child Health Survey (Zubrick et al., 2005) indicated that Indigenous youth have a higher overall incidence of mental health problems than non-Indigenous young people. Twenty-six percent of Indigenous young people compared to $17 \%$ of non-Indigenous children in 
the 4-11 year age group were shown to be at high risk of suffering mental health difficulties. Of even greater concern, $21 \%$ of Indigenous $12-17$ year olds were likely to be at risk compared with $13 \%$ of non-Indigenous youth. However, the prevalence of anxiety indicated by these data is not reported separately nor is it reported in the recent National Survey of Young Australians (Mission Australia, 2006). However, it is known from epidemiological studies in the general population that up to $18 \%$ of young people suffer from one or more anxiety disorders (Costello et al., 2003; Ford, et al., 2003).

\section{Consequences of anxiety}

Anxiety disorders in youth have been shown to reduce academic achievement (Ialongo et al., 1995), contribute to peer relationship problems (Strauss, et al., 1987) and to impairments in general social competence (Messer \& Beidel, 1994). Excessive school absenteeism and impaired peer relationships associated with anxiety also lead to poor vocational adjustment (Hibbert et al., 1990) and selfconcept problems (Asher \& Coie, 1990), as well as psychiatric disorders later in life (Kovacs \& Devlin, 1998). In addition, anxious children do not necessarily grow out of their discomfort (Kendall \& Ollendick, 2004; Pine et al., 1998) with many becoming anxiety-disordered adults (Ollendick \& King, 1994).

There is preliminary evidence to suggest that anxiety disorders may predispose adolescents to developing substance use disorders (Burke, et al.,1994; Deas-Nesmith, et al.,1998; Rodhe, et al.,1996). Additionally, adolescent mood disorders have been shown to increase the risk of adult substance abuse disorders (Deykin, et al.,1992). Research has also shown that anxiety is linked to depression (Costello \& Angold, 1995; Manassis \& Menna, 1999) and in some cases can lead to suicide (Wicks-Nelson \& Israel, 1997). This is significant for Indigenous youth, as suicide rates in this group are disproportionately higher than for non-Indigenous youth. While it is now believed that there are suicide risk factors that are uniquely Aboriginal (Westerman \& Vicary, 2000), mainstream factors such as anxiety and depression also need to be considered.

\section{Why prevention intervention?}

It is important therefore to be able to prevent the enormous economic, personal and social cost of anxiety for young people and the community. Preventive intervention designed to reduce the number of new cases of a disorder (Munoz, et al.,1996) or to reduce symptoms (Ginsburg, 2004) is often described by the three levels of universal, selected and indicated. These levels target different populations (Mrazek \& Haggerty, 1994). Universal prevention targets an entire population or group and does not consider individual risk; selective prevention strategies are offered to people at risk of suffering from a disorder; and indicated interventions target those who exhibit early symptoms that suggest a predisposition towards developing a disorder. Thus, it is important to focus on a general population health approach, including anxiety prevention programs in the school curriculum, and providing targeted intervention for at risk and indicated groups. 


\section{Evidence for anxiety prevention to date}

The most evidenced-based universal anxiety prevention program is the FRIENDS program (Barrett, et al., 1998). This program can be implemented in school as part of the curriculum and has been shown to be effective in reducing anxiety symptoms at one year follow-up (Lowry-Webster, et al., 2003). An indicated anxiety prevention program was run in the United States by LaFreniere and Capuano (1997) for mothers and preschool children in an at-risk group who were showing anxious and withdrawn behaviour. Although the intervention group showed improvements, there were significant reductions in anxious and withdrawn behaviour in the control group as well. Two Australian selected anxiety intervention programs which have shown encouraging results are the Queensland Early Intervention and Prevention of Anxiety Project (Dadds et al.,1999) for children between 7 and 14 years who showed mild anxiety symptoms. Differences between this group and the control group were non-significant at the end of the process, but at the 6 month follow up only the intervention group had maintained improvement. Cool Kids is also an example of an indicated or selected Australian anxiety prevention program which has shown some positive results (Rapee et al., 2000).

\section{Application to other cultures}

There is scant research into applying anxiety prevention programs to minority youth populations. A pilot study was conducted by Barrett et al. (2000) using the FRIENDS program for prevention of anxiety in former Yugoslavian adolescent refugees. The study found that the nine participants in the program reported less anxiety symptoms than the 11 wait list control. Promising results were also shown by the FRIENDS program with children from Yugoslavian, Chinese and mixed ethnic backgrounds (Barrett, et al., 2001). In 2005, Cool Kids was also used without adaptation in a low socio-economic area and demonstrated its effectiveness (Mifsud $\&$ Rapee, 2005). The only study to date which seems to have specifically modified a group CBT program was conducted in the United States by Ginsburg and Drake (2002) for six anxious low-income, African-American adolescents. It is surprising, however, that no Australian Indigenous young people have been studied, especially as both FRIENDS and Cool Kids were developed in Australia.

\section{Risk and protective factors for Indigenous youth}

Preventive programs should be based on risk and protective factors (Ginsburg, 2004; Donovan \& Spence, 2000) and not just adaptations of treatment programs. Although there are no incidence studies of anxiety disorders in Indigenous youth, this group is exposed to many anxiety-provoking stressors, especially challenging socioeconomic and social issues. Ongoing anger, loss and grief felt by Indigenous people resulting from their original dispossession following colonisation still affect their wellbeing. The Bringing Them Home report (Human Rights and Equal Opportunity Commission, 1997) showed that forced separation and institutionalisation of Indigenous people resulted in health problems and a range of emotional distress, including anxiety in adults. Further, children of depressed parents were more likely to show higher levels of anxiety and depressive symptoms. Generational poverty 
(Payne, 1996; Saggers \& Gray, 1991) also contributes to psychosocial stress. The Human Rights and Equal Opportunity Commission (2005) states that social and economic disadvantage places Indigenous youth at greater risk of behavioural and environmental health risks, affects physical and mental health, and encourages selfdestructive tendencies. In addition, WHO (2002) includes anxiety as one of the many psychological problems linked to exposure to violence. It is significant; therefore, that $32.7 \%$ of Indigenous 11-14 year olds reported being concerned about physical or sexual abuse (Mission Australia, 2005).

The recent Western Australian Aboriginal Child Survey (Zubrick et al., 2005) indicates that $24 \%$ of Aboriginal children aged 4 to 17 years are at a high risk of suffering clinically significant emotional or behavioural difficulties. Factors linked to this were the number of major life stress events experienced in the previous 12 months; family and household factors, specifically, dysfunctional families and poor quality parenting; being in the care of a sole parent or people other than their original parents and having lived in five or more homes; being subjected to racism in the past six months; physical health of the child and carers; speech impairment; severe otitis media; vision problems; carer access to mental health services; and smoking and marijuana use. In addition, disruption, forceful removal, substance abuse, social isolation, and cultural identity and racism have been found to be suicide risk factors for Aboriginal populations (Westerman \& Vicary, 2000).

Although these risk factors could indicate that excessive anxiety in Indigenous youth is extremely common, this needs to be balanced by examining protective factors. These have been found for youth living in homes with high household occupancy levels and when carers are both the original parents (Zubrick et al., 2005). Participation in organised sport was also seen as being beneficial as it, in particular, improved self-esteem. In extremely isolated places it was suggested that traditional culture and ways of life may be protective. Pedersen and Walker (2000) also suggest that the self-concept of Aboriginal children in remote areas is high, possibly because of Aboriginal community support, although specific factors are not elaborated. This protection is particularly important, as Trewin and Madden (2005) report that Indigenous people living in remote areas are more than twice as likely to have experienced multiple stressors.

Furthermore, drawing on literature that identifies protective factors for children at high risk, and also on preliminary research done in Western Australia, Westerman and Vicary (2000) discuss several factors in the mediation of psychosocial problem development in Indigenous youth. These include positive, adaptable temperaments, well developed problem solving and coping skills, and a strong desire to succeed. Pride in culture, hope for the future and sporting skills also seem to be protective. Attachment to at least one caregiver seems to be important, as is positive contact with peers.

\section{Prevention programs for Indigenous youth}

While trauma from historical injustices and effects of socio-economic issues remain unresolved in Indigenous communities, preventative mental health programs will 
have only limited benefits. Despite this, prevention strategies still need to be developed to address this problem (Lette et al., 2000). A wide variety of issues must be considered if culturally sensitive, preventative anxiety programs are to be developed or adapted for use with Indigenous youth.

\section{Differing mental health conceptions}

For any prevention program to succeed it is imperative that all people involved must consider the programs as important (Hunter, 1998), as when people are living in adverse circumstances prevention may not be considered to be a high priority. Differing models of prevention or proactive programs also need to be explored, as well as differences between Western and Indigenous concepts of mental health. Research in the general population indicates that cognitive behaviour therapy is an effective treatment for young people suffering anxiety (Ollendick \& King, 1998; 2000). Indigenous people who have belief systems that encompass holistic concepts of mental health, may not recognise health as a mind and body connection (Slattery, 1994). Vicary and Bishop (2005) report that Aboriginal people are sometimes unaware of mental health implications due to the concept of mental illness being unfamiliar or something not discussed in the community. In addition, physical signs or moods are not necessarily attributed to feelings (Roe, 2000), but can be associated with culturally based external wrongdoing (Reid \& Trompf, 1991; Westerman, 2003) or character traits (Vicary \& Bishop, 2005), making most Western anxiety prevention programs based on cognitive behaviour therapy of little use to many Indigenous people (Westerman, 2004). In a Western Australian study looking at Aboriginal conceptualisations of mental health, Vicary and Bishop (2005) found that study participants were frustrated by Western therapies that encouraged them to selfexplore. This may have significant implications and limit intervention options available to schools as self-exploration is a basis for most intervention programs.

\section{Stigma}

The process of identifying young people for indicated or selected prevention programs has stigma implications for most students, and even more so for Indigenous students. Lette et al. (2000), report that while young Aboriginal people with profound worries are an important target population, they tend not to access helping agencies or schools, largely due to feelings of shame they experience when they are not coping. This appears to be related to the stigma of being labelled as having a mental health problem and the fear of social rejection that may follow. Therefore, while there is a tendency not to seek help outside their cultural community, due to concerns about communication, understanding and confidentiality, they also hesitate to seek help within the community due to concerns about confidentiality and being labelled. This has major implications for the development and implementation of programs, as young Indigenous people may not feel comfortable enough to participate. If these hurdles can be overcome, there are numerous other factors to consider in assessment, program design, implementation and review as discussed below. 


\section{Identification}

While accurately assessing anxiety in children and adolescents is generally complex (Campbell \& Rapee, 1996), when the participants are Indigenous further complications may arise. Bias, validity and reliability concerns have long been an area of contention due to cultural issues that can misrepresent abilities or states of mental health (Drew, 2000). It has been suggested that any assessment is culturally biased unless it takes into account all factors for the development and maintenance of the problem, and the results of intervention. Difficulties obtaining an accurate picture of functioning can include the use of culturally biased assessment tools, inappropriate comparison of data, a poor relationship between the assessor and the participant, the assessment setting, whether similar performance is seen in the cultural context, and recognition of cultural factors such as culture-bound syndromes or differences in conceptualisation of mental health (Westerman, 2002a).

One culturally appropriate psychological measure that has been validated for use with Indigenous youth in Australia is the Westerman Aboriginal Symptom Checklist-Youth (WASC-Y), (Westerman, 2002b; 2003). This is a tool for early identification of depression, anxiety, suicidal behaviours and self esteem problems in Aboriginal young people in the 13 to 17 year old group. In conjunction, Westerman (2003) has developed a model to assist in considering cultural factors that affect validity in assessments. Future research into Indigenous mental health will probably rely on more measures such as this being developed.

\section{Some suggestions for Indigenous prevention of anxiety}

Thus, if preventative anxiety programs are to be considered culturally appropriate, they must include Indigenous constructions of reality and involvement of Indigenous people (Dudgeon \& Williams, 2000) from the initial assessment through to intervention and evaluation (Garvey, 1994). The program development, therefore, requires extensive consultation with the Indigenous community, including the young people for whom it is intended. This will help to ensure that it is meaningful and that there is ownership of both the materials produced and strategies for use or distribution (Lette et al., 2000).

\section{Culturally appropriate engagement and cultural consultants}

Vicary and Bishop (2005) proposed a model of intervention that engages Aboriginal people in culturally appropriate ways. While it is involved and time-consuming, it increases the likelihood of successful engagement. The model is strongly focused on building relationships and trust, and developing networks. It requires nonjudgmental practice and modification of counselling skills-primarily the use of language. Central to the model is the use of a cultural consultant, a person chosen by the community to assist with networking and cultural understanding throughout program development and beyond. It is therefore likely that the involvement of cultural consultants in the development and dissemination of programs, or vouching for any non-Indigenous person presenting a program, would be more successful. This is particularly pertinent if there is to be acceptance and understanding that all communities are different (Sambono, 1993). Dudgeon et al. (2000) further suggest 
the presence of Aboriginal people in programs is essential due to shared life experiences. This could present a difficulty in universal prevention programs if there are Indigenous and non-Indigenous students in the same class.

\section{Proposed approaches}

Initially, Kearins (2000) discusses a number of cultural factors with implications for those teaching Indigenous children. These include social behaviour differences, language, specific learning differences and preferred learning styles. Gaining some understanding of these factors will enhance success in working with Indigenous students.

Some options for overcoming sadness or worries recommended in the 1999 Ruah Inreach Project (Lette et al., 2002) that may have application in schools included activity-based challenges, connecting to the land, cultural activities and art. Mason (2000) suggests that art and art therapy can assist Indigenous people to find their cultural beliefs and values. This may significantly reduce anxiety. In addition, Rydberg (2001) maintains that art gives children the opportunity to express fear and confusion non-verbally. Similarly, play may be used as an intervention as it is universal to all cultures. In additional to developmental benefits (Reddy et al., 2005), play has been used to alleviate emotional issues with moderate to large positive effects (LeBlanc \& Ritchie, 1999; Ray et al., 2001).

Despite the concerns about young people not wishing to speak about their difficulties, narrative, personal stories, anecdotes, and yarning are the therapies suggested most often by Aboriginal writers (Burke, 2007). Narrative therapy has been adapted with success for use with Indigenous peoples (Aboriginal Health Council of South Australia, 1995). It reflects Indigenous oral traditions and provides an outlet for alternative stories of marginalised people to be told, thereby empowering them (White, 1997; Solomon, 2005) and may have applications in assisting anxious Indigenous youth.

One model that may have wide application in schools for developing support programs is the Holistic planning and teaching framework (Grant, 1998; Indigenous Schooling Support Unit, 2007), developed for use by teachers with Indigenous students. The framework links land, language and culture to time, place and relationships, to organise and present information holistically. This fits the Aboriginal worldview and reflects Indigenous beliefs about mental health and connectedness, as opposed to the Western tendency to compartmentalise information. When students learn about the importance of the interconnectedness of all aspects of their lives, emotional difficulties may be meaningfully addressed.

\section{The need for more research}

While there are still significant gaps in our knowledge of anxiety disorders and youth in the general population, this is more so for cultural groups and minority youth for whom the complexities of assessment and prevention are barriers to wellness. The paucity of accurate and current information on the prevalence of 
anxiety in Australian Indigenous youth is of great concern, and culturally appropriate research is required to determine extent of this disorder and effective prevention options. Hunter (2002) and Westerman (2004) refer to the desperate need for mental health preventative strategies for all Indigenous people (Cleworth et al., 2006) and there are increasing calls for education systems to support Indigenous students with emotional difficulties (Craven \& Bodkin-Andrews, 2006; Zubrick et al., 2006). While universal programs are needed, schools also have a role to play in targeted early intervention programs to support youth at risk of psychological problems such as anxiety. Selected and indicated preventative interventions are not possible without being able to identify individuals or groups at risk, and programs that will be effective. Further research is urgently required to inform intervention and prevention strategies in educational settings (Craven \& Marsh, 2004).

\section{References}

Aboriginal Health Council of South Australia, 1995, 'Reclaiming our stories, reclaiming our lives: An initiative of the Aboriginal Health Council of South Australia'. Dulwich Centre Newsletter,1, 1-40.

Asher SR \& Coie JD (eds), 1990, Peer rejection in childhood. Cambridge University Press, New York.

Barrett PM, Lowry-Webster, HM \& Holmes JM, 1998, FRIENDS program for children: Group leader's manual. Australian Academic Press, Brisbane.

Barrett PM, Moore AF \& Sonderegger R, 2000, 'The FRIENDS program for young former-Yugoslavian refugees in Australia: a pilot study'. Behaviour Change, 17, 124-33.

Barrett PM, Sonderegger R \& Sonderegger NL, 2001, 'Evaluation of an anxietyprevention and positive-coping program (FRIENDS) for children and adolescents of non-English speaking background'. Behaviour Change, 18, 78-91.

Burke JD, Burke KC \& Rae DS, 1994, 'Increased rates of drug abuse and dependence after onset of mood or anxiety disorders in adolescence'. Hospital and Community Psychiatry, 45, 451-5.

Burke S, 2007, 'Changing practices, changing paradigms: Working effectively with Indigenous clients'. InPsych, 29(1), 14-5.

Campbell MA \& Rapee RM, 1996, 'Current issues in the assessment of anxiety in children and adolescents: A developmental perspective'. Behaviour Change,13, 185-93. 
Cleworth S, Smith W \& Sealy R, 2006, 'Grief and courage in a river town: A pilot project in the Aboriginal community of Kempsey, New South Wales'. Australasian Psychiatry, 14, 390-4.

Costello EJ \& Angold A, 1995, 'Epidemiology'. In March JS (ed.), Anxiety disorders in children and adolescents. Guilford Press, New York, 109-24.

Costello EJ, Mustillo S, Erkanli A, Keeler G \& Angold A, 2003, 'Prevalence and development of psychiatric disorders in childhood and adolescence'. Archives of General Psychiatry, 60, 837-44.

Craven RG \& Bodkin-Andrews G, 2006, 'New solutions for addressing Indigenous mental health: A call to counsellors to introduce the new positive psychology of success'. Australian Journal of Guidance \& Counselling, 16, 41-54.

Craven RG \& Marsh HW, 2004, 'The challenge for counsellors: understanding and addressing Indigenous secondary students' aspirations, self-concepts and barriers to achieving their aspirations'. Australian Journal of Guidance \& Counselling, 14, 16-33.

Dadds MR, Holland DE, Laurens KR, Mullins M, Barrett PM \& Spence SH, 1999, 'Early intervention and prevention of anxiety disorders in children: results at 2-year follow-up'. Journal of Consulting and Clinical Psychology, 67, 14550.

Deas-Nesmith D, Brady KT \& Campbell S, 1998, 'Comorbid substance use and anxiety disorders in adolescents'. Journal of Psychopathology \& Behavioral Assessment, 20, 139-48.

Deykin E, Buka S, \& Zeena T, 1992, 'Depressive illness among chemically dependent adolescents'. American Journal of Psychiatry, 149, 1341-7.

Donovan CL \& Spence SH, 2000, 'Prevention of childhood anxiety disorders'. Clinical Psychology Review, 20, 509-31.

Drew N, 2000, 'Psychological testing with Indigenous people in Australia'. In Dudgeon P, Garvey D \& Pickett H (eds), Working with Indigenous Australians: A handbook for psychologists. Gunada Press, Perth, 325-34.

Dudgeon P, 2000, 'Diversity in Aboriginal culture'. In Dudgeon P, Garvey D \& Pickett H (eds), Working with Indigenous Australians: A handbook for psychologists. Gunada Press, Perth, 137-42.

Dudgeon P, Garvey D \& Pickett H, 2000, 'A cultural history'. In Dudgeon P, Garvey D \& Pickett H (eds), Working with Indigenous Australians: A handbook for psychologists. Gunada Press, Perth, 27-30. 
Dudgeon P \& Williams R, 2000, 'Culturally appropriate therapies, models and services'. In Dudgeon P, Garvey D \& Pickett H (eds), Working with Indigenous Australians: A handbook for psychologists. Gunada Press, Perth, 395-402.

Ford T, Goodman R \& Meltzer H, 2003, 'The British child and adolescent mental health survey 1999: the prevalence of DSM-IV disorders'. Journal of the American Academy of Child and Adolescent Psychiatry, 42, 1203-11.

Garvey D, 1994, 'Some dimensions of "cultural appropriateness"-implications of Aboriginal terms of reference for psychological research and therapy'. Paper presented at the National Conference of the Australian Psychological Society, Perth, WA.

Ginsburg GS, 2004, 'Anxiety prevention programs for youth: practical and theoretical considerations'. Clinical Psychology: Science and Practice, 11, $430-4$.

Ginsburg GS \& Drake KL, 2002, 'School-based treatment for anxious AfricanAmerican adolescents: a controlled pilot study'. Journal of the American Academy of Child and Adolescent Psychiatry, 41, 768-76.

Grant E, 1998, My land. My tracks. Innisfail \& District Education Centre, Innisfail, Queensland.

Hibbert A, Fogelman K \& Manor O, 1990, 'Occupational outcomes of truancy'. British Journal of Educational Psychology, 60, 171-9.

Human Rights and Equal Opportunity Commission, 1997, 'Bringing them home: Report of the national inquiry into the separation of Aboriginal and Torres Strait Islander children from their families'. Author, Canberra.

Human Rights and Equal Opportunity Commission, 2005, 'Native Title 2005, A statistical overview of Aboriginal and Torres Strait Islander peoples in Australia'. <www.hreoc.gov.au/social_justice/statistics/> viewed December 2007.

Hunter EM, 1998, 'Early intervention for Indigenous social and emotional health problems'. AusEinetter, 5, 1-2.

Hunter EM, 2002, “Best intentions" lives on: untoward health outcomes of some contemporary initiatives in Indigenous affairs'. Australian and New Zealand Journal of Psychiatry, 36, 575-84.

Ialongo N, Edlesohn G, Werthamer-Larsson I, Crockett I \& Kellam S, 1995, 'The significance of self-reported anxious symptoms in first grade children: prediction to anxious symptoms and adaptive functioning in fifth grade'. Journal of Child Psychology and Psychiatry, 36, 427-37. 
Indigenous Schooling Support Unit (Producer), 2007, 'Holistic planning and teaching framework'. DVD, Department of Education, Training and the Arts, Cairns.

Kearins J, 2000, 'Children and cultural difference'. In Dudgeon P, Garvey D \& Pickett H (eds), Working with Indigenous Australians: a handbook for psychologists. Gunada Press, Perth, 167-76.

Kendall PC \& Ollendick TH, 2004, 'Setting the research and practice agenda for anxiety in children and adolescence: a topic comes of age'. Cognitive and Behavioural Practice, 11, 65-74.

Kovacs M \& Devlin B, 1998, 'Internalizing disorders in childhood'. Journal of Child Psychology and Psychiatry, 39, 17-63.

LaFreniere PJ \& Capuano F, 1997, 'Preventive intervention as a means of clarifying direction of efforts in socialization: anxious withdrawn preschoolers case'. Development and Psychopathology, 9, 551-64.

LeBlanc M \& Ritchie M, 1999, 'Predictors of play therapy outcomes'. International Journal of Play Therapy, 8(2), 19-34.

Lette H, Wright M \& Collard S, 2000, 'Aboriginal youth: mental health'. In Dudgeon P, Garvey D \& Pickett H (eds), Working with Indigenous Australians: a handbook for Psychologists. Gunada Press, Perth, 91-102.

Lowry-Webster HM, Barrett PM \& Lock S, 2003, 'A universal prevention trial of anxiety symptomology during childhood: results at 1-year follow-up'. Behaviour Change, 20, 25-43.

Mason S, 2000, 'Art therapy'. In Dudgeon P, Garvey D \& Pickett H (eds), Working with Indigenous Australians: a handbook for psychologists. Gunada Press, Perth, 431-438.

Manassis K \& Menna R, 1999, 'Depression in anxious children: possible factors in comorbidity'. Depression and Anxiety, 10, 18-24.

Messer S \& Beidel D, 1994, 'Psychosocial correlates of childhood anxiety disorders'. Journal of the American Academy of Child and Adolescent Psychiatry, 33, 975-83.

Mission Australia, 2005, 'National youth survey: key and emerging issues', Author, Sydney.

Mission Australia, 2006, 'National youth survey: key and emerging issues'. Author, Sydney. 
Mifsud C \& Rapee RM, 2005, 'Early intervention for childhood anxiety in a school setting: outcomes for an economically disadvantaged population'. Journal of the American Academy of Child and Adolescent Psychiatry, 44, 996-1004.

Mrazek PJ \& Haggerty RJ, 1994, 'Committee on prevention of mental disorders'. National Academy Press, Washington, DC.

Munoz RF, Mrazek PJ \& Haggerty RJ, 1996, 'Institute of Medicine report on the prevention of mental disorders: summary and commentary'. American Psychologist, 51, 1116-22.

Ollendick TH \& King NJ, 1994, 'Diagnosis, assessment, and treatment of internalising problems in children: the role of longitudinal data'. Journal of Consulting and Clinical Psychology, 62, 918-27.

Ollendick TH \& King NJ, 1998, 'Empirically supported treatments for children with phobic and anxiety disorders: current status'. Journal of Clinical Child Psychology, 27, 156-67.

Ollendick TH \& King NJ, 2000, 'Empirically supported treatments for children and adolescents'. In Kendall PC (ed.), Child and adolescent therapy: cognitive and behavioral procedures. The Guilford Press, New York, 386-425.

Payne R, 1996, A framework for understanding poverty, aha! Process, Texas.

Pederson A \& Walker I, 2000, 'Urban Aboriginal-Australian and Anglo-Australian children: self concept and teacher's academic evaluations'. Journal of Community and Applied Social Psychology, 10, 183-97.

Pine D, Cohen P, Gurley D, Brook J \& Ma Y, 1998, 'Risk for early adulthood anxiety and depressive disorders in adolescents with anxiety and depressive disorders'. Archives of General Psychiatry, 55, 55-64.

Rapee RM, Wignall A, Hudson JL \& Schniering CA, 2000, Evidence-based treatment of child and adolescent anxiety disorders, New Harbinger Publications, Oakland, CA.

Ray D, Bratton S, Rhine T \& Jones L, 2001, 'The effectiveness of play therapy: Responding to the critics'. International Journal of Play Therapy, 10(1), 85108.

Reddy LA, Files-Hall TM \& Schaefer CE, 2005, 'Announcing empirically based play interventions for children'. In Reddy LA, Files-Hall TA \& Schaefer CE (eds), Empirically based play interventions for children. American Psychological Press, Washington, DC, 3-10.

Reid JT \& Trompf P, 1991, The health of Indigenous Australia, Harcourt Brace and Jovanovich, Marrickville. 
Rodhe P, Lewinsohn PM \& Selby JR, 1996, 'Psychiatric comorbidity with problematic alcohol use in high school students'. Journal of the American Academy of Child and Adolescent Psychiatry, 35, 101-9.

Roe J, 2000, 'Cultural empowerment: Ngarlu-a cultural and spiritual strengthening model'. In Dudgeon P, Garvey D \& Pickett H (eds), Working with Indigenous Australians: a handbook for psychologists. Gunada Press, Perth, 395-402.

Rydberg TS, 2001, 'The use of art making in addressing fears and anxiety of children after traumatic events'. Connections, 3(1), 12-5.

Saggers S \& Gray D, 1991, Aboriginal health \& society: the traditional and contemporary Aboriginal struggle for better health. Allen \& Unwin, St Leonards.

Sambono H, 1993, 'Providing mental health services to Aboriginal communities'. Mental Health In Australia, 5(2), 42-5.

Slattery G, 1994, 'Transcultural therapy with Indigenous families: working in the belief system'. Australian \& New Zealand Journal of Therapy, 8(3), 61-70.

Solomon G, 2005, 'Development of art therapy in South Africa: dominant narratives and marginalised stories'. International Journal of Art Therapy, 10(1), 3-13.

Strauss CC, Frame CL \& Forehand RL, 1987, 'Psychosocial impairment associated with anxiety in children'. Journal of Clinical Child Psychology, 16, 235-9.

Trewin D \& Madden R, 2005, The health and welfare of Australia's Aboriginal and Torres Strait Islander peoples. Australian Bureau of Statistics, Canberra.

Vicary D \& Bishop B, 2005, 'Western psychotherapeutic practice: Engaging Aboriginal people in culturally appropriate and respectful ways'. Australian Psychologist, 40(1), 8-19.

Westerman T, 2002a, Measurement of mental health problems in Aboriginal and Torres trait Islander populations, Powerpoint presentation <auseinet.flinders.edu.au/resources/auseinet/forum02/westerman.ppt> viewed January 2006.

Westerman T, 2002b, Westerman Aboriginal Symptom Checklist-Youth. Indigenous Psychological Services, Perth.

Westerman T, 2003, 'Development of an inventory to assess the moderating effects of cultural resilience with Aboriginal youth at risk of depression, anxiety and suicidal behaviours'. PhD thesis, School of Psychology, Curtin University, Perth, WA. 
Westerman T, 2004, 'Engagement of Indigenous clients in mental health services: What role do cultural differences play?' Australian e-Journal for the Advancement of Mental Health, 3(3), 1-7.

Westerman T \& Vicary D, 2000, 'Aboriginal youth suicide'. In Dudgeon P, Garvey D \& Pickett H (eds), Working with Indigenous Australians: A handbook for psychologists. Gunada Press, Perth, 471-9.

White M, 1997, Narratives of therapists lives, Dulwich Centre Publication.

Wicks-Nelson R \& Israel A, 1997, Behaviour disorders of childhood (3rd edn), Prentice-Hall, London.

World Health Organisation, 2002, World report on violence and health: Summary, Author, Geneva.

Zubrick S, Silburn S, Lawrence D, Mitrou F, Dalby R, Blair E, Griffin JA et al., 2005, The Western Australian Aboriginal child health survey: The social and emotional wellbeing of Aboriginal children and young people. Curtin University of Technology and Telethon Institute for Child Health Research, Perth.

Zubrick S, Silburn S, De Maio JA, Shepherd C, Griffin JA, Dalby RB, Mitrou FG et al., 2006, The Western Australian Aboriginal child health survey: Improving the educational experiences of Aboriginal children and young people. Curtin University of Technology and Telethon Institute for Child Health Research, Perth. 